\title{
Racial Demographics in an Urban Movement Disorders Clinic
}

\section{Chantale 0. Branson1, Luke Quehl'2, Raymond James1, Janice Weinberg', Anna D. Hohler1, Marie-Helene Saint-Hilaire ${ }^{1}$}

\author{
${ }^{1}$ Department of Neurology, Boston University Medical Center, Boston, MA, USA \\ ${ }^{2}$ Boston University School of Medicine, Boston, MA, USA \\ ${ }^{3}$ Boston University School of Public Health, Boston, MA, USA \\ Email: cmurray@bu.edu, lquehl@bu.edu,rcjames@bu.edu, janicew@bu.edu, anna.hohler@bmc.org, marie.saint-hilaire@bmc.org
}

How to cite this paper: Branson, C.O. Quehl, L., James, R., Weinberg, J., Hohler, A.D. and Saint-Hilaire, M.-H. (2017) Racial Demographics in an Urban Movement Disorders Clinic. Advances in Parkinson's Disease, 6, 86-92.

https://doi.org/10.4236/apd.2017.63009

Received: July 12, 2017

Accepted: August 14, 2017

Published: August 17, 2017

Copyright (C) 2017 by authors and Scientific Research Publishing Inc. This work is licensed under the Creative Commons Attribution International License (CC BY 4.0).

http://creativecommons.org/licenses/by/4.0/

\begin{abstract}
Objective: To assess the prevalence of Parkinson's disease (PD) among African-Americans compared to non-Hispanic Whites in a tertiary urban Movement Disorders center. Background: Contributing factors in the prevalence of Parkinson's disease (PD) based on race may improve health disparities in the United States. According to the largest study analyzing prevalence and incidence of PD among Medicare beneficiaries, the ratio of African-Americans (AA) to Caucasians in the general Medicare population is $9 \%$, while the prevalence ratio of $\mathrm{PD}$ among AA compared to Caucasians is approximately $5 \%$. Methods: We performed a retrospective analysis of African-American patients with PD in the movement disorders database at Boston Medical Center, which is the largest safety net hospital in New England. The demographics of the patients seen in the general neurology clinic are 30.57\% AA and $38.06 \%$ non-Hispanic Caucasian. Results: The Movement disorders database included 488 patients, 327 of whom had PD. Of these, 287 were Caucasians and 18 were of African descent. Based on our clinic population the expected PD case ratio among AA compared to Caucasians was approximately $49 \%$. The actual race ratio in patients of African descent compared to Caucasian was 6\%, which was substantially lower than expected at Boston Medical Center. Conclusion: The demographics of the PD patients in our movement disorders clinic do not reflect the population at Boston Medical Center, or the demographics of our neurology clinic as a whole.
\end{abstract}

\section{Keywords}

Racial Demographics, Urban Movement Disorders Clinic 


\section{Introduction}

Parkinson's disease (PD) is a progressive neurodegenerative disorder diagnosed primarily by clinical presentation and neurological examination. The prevalence of PD among the elderly population is approximately $1.6 \%$ [1]. The etiology and prevalence of PD is probably in most cases multifactorial with genetic and environmental risk factors. The most contributing factors of PD include age, sex, geographic location and race [1]. There is still limited knowledge in how race affects incidence of PD. African-Americans (AA) are diagnosed with PD at half the rate of Caucasians after controlling for age, sex, location of care, healthcare use, and reason for Medicaid eligibility [2].

The difference in incidence rate of PD in AA compared to whites has not been explained so far by insurance, income, location of care, or healthcare utilization. Further analyses have been recommended to find other potential causes, such as patient, physician and system factors. There have also been several studies analyzing patient perception and knowledge of $\mathrm{PD}$ among racial and ethnic groups. African-Americans were less likely to report PD related disability compared to whites based on a small sample size of PD patients using the Unified Parkinson Disease Rating Scale (UPDRS) [3]. Understanding PD based on racial and ethnic groups may provide insight into recognizing disparities of diagnosis. Pan et al. completed a mixed-methods cross-sectional study involving PD focus groups and survey study distributed to senior centers in Philadelphia, Pennsylvania. The study revealed a lack of understanding about PD symptoms, fear of the diagnosis and concern of becoming a burden to family [4].

However, under-reporting of PD symptoms does not entirely explain disparities in PD treatment [5] [6] [7]. Another possible cause of delay in diagnosis may include a lack of referral from primary care physicians. Studies have shown that initial diagnosis of Parkinson's disease is done generally by the primary care [8]. Analyzing the PD referrals of patients of African descent compared to Caucasians in a Movement Disorders clinic at an urban academic center serving a large number of AA may provide understanding for the delay in diagnosis.

Boston Medical Center is the largest safety net hospital in New England, as $59 \%$ of the population it serves is disadvantaged due to lack of access to care, race, ethnicity and social factors. The proportions of Blacks or AA and Whites or Caucasians in the population seen at the hospital were respectively $29.1 \%$ and $33.6 \%$ in 2011. The demographics of patients seen in the general neurology clinic are similar to the overall population at Boston Medical Center (AA 30.57\% and Caucasians 38.06\%) (Table 1). Therefore, the movement disorders clinic should have a comparable proportion of AA with idiopathic PD compared with Caucasians if incidence were the same in the two populations. Based on a study that analyzed the prevalence and incidence of Parkinson's disease per year in the United States Medicare beneficiary database, we expect that the incidence of PD in our African-American population would be about half of what it is in Caucasians [1]. This study, which was the largest to date analyzing incidence and pre- 
Table 1. Outpatient Neurology Visits at Boston Medical Center 10/24/2015-10/24/2016.

\begin{tabular}{ccc}
\hline RACE & N & Total \% \\
\hline Asian & 324 & $7.95 \%$ \\
American Indian/Native American & 91 & $0.69 \%$ \\
Black/African American & 4034 & $30.57 \%$ \\
Declined/Not Available & 3703 & $28.10 \%$ \\
Hispanic or Latino & 4 & $0.03 \%$ \\
Native Hawaiian/Pacific Islander & 15 & $0.11 \%$ \\
White & 5022 & $38.06 \%$ \\
(blank) & 1 & $0.007 \%$ \\
\hline
\end{tabular}

valence of PD by race, age, sex and county, reported that the prevalence ratio of $\mathrm{PD}$ among African-Americans compared to Caucasians in the general Medicare population is about $5 \%$.

\section{Methods}

Data were abstracted from the movement disorders database from the Boston University Neurology Department. The database includes patients seen in the outpatient neurology clinic who have a known diagnosis of Parkinsonism. Data recorded include demographics, race, ethnicity, date of onset of symptoms, date of diagnosis and insurance. Racial demographics are divided into ethnicity including African-Black, -North and American-Black. The diagnosis is confirmed by a Movement Disorders specialist within the neurology clinic at Boston Medical Center. The ratio of cases in the database was compared to the Medicare population-based study of Parkinson's disease [1]. The Institutional Review Board at Boston University reviewed and approved the protocol.

\section{Data Analysis}

The prevalence ratio of $\mathrm{PD}$ among AA compared to Caucasians in the general population is about $9 \%$ based upon the Willis article. The expected case ratio in our population was determined by multiplying the prevalence ratio of AA compared to Caucasians at Boston Medical Center in 2016, by the PD prevalence ratio of AA compared to Caucasians based on the Willis article. This expected rate was compared to the actual case ratio of AA compared to Caucasians with PD in our database.

\section{Results}

Of the 488 patients were in the movement disorders database, 327 patients were diagnosed with idiopathic PD and 161 were diagnosed with other neurological disorders. There were 45 patients of African descent (sub-Sahara, northernAfrica and African-American) in the database. Of these 45 patients, 18 or $40 \%$ were diagnosed with idiopathic PD. There were 393 Caucasian patients in the 
database. Of these, two hundred and eighty seven or $73 \%$ were diagnosed with idiopathic PD (Table 2).

Calculation of the expected case ratio was based upon the Willis et al. study, which demonstrated a prevalence ratio for PD of 0.58 [1]. The prevalence ratio of PD multiplied by the prevalence ratio of PD at Boston Medical Center in African-Americans (including Hispanic/Latino/Spanish) was 8532, and in White (Not Hispanic/Latino/Spanish) 10,082. The expected race (case) ratio of AA at Boston Medical Center is therefore $0.58 \times(0.84)=0.49$ or $49 \%$. The actual case ratio of AA patients in the Boston Medical Center Movement Disorder database was $11 \%$, and among patients with a diagnosis of idiopathic PD it was even lower at $6 \%$, despite the large population of AA in the general Neurologic clinic.

\section{Strengths and Limitations}

Although this study provided a larger proportion of Africans-Americans compared with non-Hispanic Caucasians than other studies analyzing the prevalence ratio of patients with Parkinson's disease [1] [2], our sample size was small. In addition, all of the demographics at Boston Medical Center were not analyzed. The demographics were obtained for all of the patients within the database and are summarized in Table 3; the sample size was too small for additional analysis by other demographic characteristics. The strength of the study is that all of

Table 2. Racial demographics in the movement disorders database.

\begin{tabular}{cccc}
\hline RACE & $\begin{array}{c}\text { Without } \\
\text { iPD }\end{array}$ & $\begin{array}{c}\text { With } \\
\text { iPD }\end{array}$ & Total \\
\hline $\begin{array}{c}\text { African-American* } \\
\text { African-Black (Sub-Sahara) }\end{array}$ & 6 & 2 & 8 \\
$\begin{array}{c}\text { African-North (Sahara or Northern Regions: Algeria, Egypt, } \\
\text { Morocco, Tunisia, Etc.) }\end{array}$ & 2 & 2 & 4 \\
$\begin{array}{c}\text { American-Black (African descent, originating in: Canada, } \\
\text { Caribbean, Brazil, US, etc.) }\end{array}$ & 19 & 14 & 33 \\
$\begin{array}{c}\text { American Indian/Alaska Native } \\
\text { Asian-East (China, Japan, Korea, etc.) }\end{array}$ & 0 & 2 & 2 \\
Caucasian \\
Mixed Race
\end{tabular}

*African-American, including African-Black (Sub-Sahara); North (Sahara or Northern regions: Algeria, Egypt, Morocco, Tunicia, etc.); American-Black (African descent, originating in: Canada, Caribbean, Brazil, US etc.). 
Table 3. Demographic characteristics of the movement disorders database.

\begin{tabular}{|c|c|c|}
\hline \multicolumn{3}{|c|}{ Patient Demographics } \\
\hline \multirow{2}{*}{ Gender } & Women & $50.2 \%(245)$ \\
\hline & Men & $49.7 \%(243)$ \\
\hline \multirow{14}{*}{ Race } & Caucasian & $80.5 \%(393)$ \\
\hline & African American: & $9.2 \%(45)$ \\
\hline & American-Black (African descent, originationg in: Canada, Carribean, Brazil, US, etc.) & $6.8 \%(33)$ \\
\hline & African-Black (Sub-Sahara) & $1.6 \%(8)$ \\
\hline & African-North (Sahara or Northern Regions: Algeria, Egypt, Morocco, Tunisia, etc.) & $0.8 \%(4)$ \\
\hline & Spanish (Cuban, Iberian Peninsula, Mexican, South or Central American, or Other Spanish Origian) & $4.7 \%(23)$ \\
\hline & Asian: & $3.7 \%(18)$ \\
\hline & Asian-East (China, Japan, Korea, etc.) & $2.5 \%(12)$ \\
\hline & Asian-West (Bangladesh, India, Iran, Iraq, Pakistan, etc.) & $1.2 \%(6)$ \\
\hline & Other-No category above reflects origin & $0.8 \%(4)$ \\
\hline & American Indian/Alaska Native & $0.4 \%(2)$ \\
\hline & Mixed Race & $0.2 \%(1)$ \\
\hline & Native Hawaiian or Other Pacific Islander & $0.2 \%(1)$ \\
\hline & Not in EMR (Declined/Not Available) & $0.2 \%(1)$ \\
\hline \multirow{8}{*}{ Education } & Bachelor's degree & $25.8 \%(126)$ \\
\hline & Graduate or Professional degree & $21.1 \%(103)$ \\
\hline & High School degree/GED & $20.9 \%(102)$ \\
\hline & Not Documented & $14.1 \%(69)$ \\
\hline & Some College, no degree & $8.4 \%(41)$ \\
\hline & $<$ High School & $3.9 \%(19)$ \\
\hline & Some High School, bo degree & $3.7 \%(18)$ \\
\hline & Associate degree & $2.0 \%(10)$ \\
\hline \multirow{7}{*}{ Occupation } & Not in the Labor Force & $69.1 \%(337)$ \\
\hline & Management, Professional, Related & $12.3 \%(60)$ \\
\hline & Sales & $5.9 \%(29)$ \\
\hline & Not Documented & $4.5 \%(22)$ \\
\hline & Service & $4.1 \%(20)$ \\
\hline & Construction, Extraction, Maintenance & $2.3 \%(11)$ \\
\hline & Production, Transport, Material Moving & $1.8 \%(9)$ \\
\hline \multirow{5}{*}{ Insurance } & Medicare or Medicaid & $53.3 \%(260)$ \\
\hline & Private & $35.7 \%(174)$ \\
\hline & Not Documented & $7.4 \%(36)$ \\
\hline & Free care & $2.7 \%(13)$ \\
\hline & Self pay & $1.0 \%(5)$ \\
\hline
\end{tabular}


the patients were examined and diagnosed by movement disorders specialists.

\section{Discussion}

The dominant contributing factors in the prevalence of Parkinson's disease (PD) include age, sex, race and geographic location [1]. An article reviewed the literature regarding racial difference in the prevalence of Parkinson's disease and how it may change the overall outcome for patients [7]. Many of the studies found a disproportionate number of AA with PD receiving less care, even when many of them received care in tertiary teaching hospitals with higher than average numbers of neurologists and neurosurgeons who may specialize in advanced treatment of PD, such as deep brain stimulation.

Boston Medical Center is also a tertiary hospital and provides care to a large proportion of AA. Therefore, it is expected that the Movement Disorders group at Boston Medical Center would also care for a large proportion of AA with PD, even taking into account the smaller incidence and prevalence of $\mathrm{PD}$ in that population. However, this is not the case based upon the analysis of our movement disorders database. Many of the patients with idiopathic PD are Caucasian and the observed ratio of AA with PD (6\% vs $49 \%$ expected) is much lower than expected. This may suggest referral bias among physicians at Boston Medical Center, which may cause an under-diagnosis of PD among African-Americans.

A recent systematic review of the literature analyzing racial disparities in $\mathrm{PD}$ analyzed the differences in PD diagnosis and treatment among AA compared to non-Hispanic Caucasians [9]. These disparities may erroneously lower the prevalence of $\mathrm{PD}$ in the AA population [10]. A few studies also analyzed the perception and knowledge of PD among racial and ethnic groups to obtain a better understanding of the disparities that were observed [4] [11]. There is however no detailed study of the physicians' perception of PD among diverse populations, so the biases that are affecting diagnosis are not well understood.

Our results further support Dahodwala et al.'s conclusion that racial differences in PD are not due to the clinical needs or appropriateness of care [2]. The lower prevalence of PD at Boston Medical Center may suggest referral bias with fewer African-Americans being referred by practitioners for evaluation and possible diagnosis of Parkinson's disease. This is important as there is a direct link between greater survival among PD patients and receiving care from a neurologist [8]. Therefore, it is essential to understand how PD patients are referred to Movement Disorders clinics to improve overall access for all ethnic and racial groups.

\section{References}

[1] Wright Willis, A., Evanoff, B.A., Lian, M., Criswell, S.R. and Racette, B.A. (2010) Geographic and Ethnic Variation in Parkinson Disease: A Population-Based Study of US Medicare Beneficiaries. Neuroepidemiology, 34, 143-151. https://doi.org/10.1159/000275491

[2] Dahodwala, N., Siderowf, A., Xie, M., Noll, E., Stern, M. and Mandell, D.S. (2009) 
Racial Differences in the Diagnosis of Parkinson's Disease. Movement Disorders, 24, 1200-1205. https://doi.org/10.1002/mds.22557

[3] Dahodwala, N., Karlawish, J., Siderowf, A., Duda, J.E. and Mandell, D.S. (2011) Delayed Parkinson's Disease Diagnosis among African-Americans: The Role of Reporting of Disability. Neuroepidemiology, 36, 150-154. https://doi.org/10.1159/000324935

[4] Pan, S., Stutzbach, J., Reichwein, S., Lee, B.K. and Dahodwala, N. (2014) Knowledge and Attitudes about Parkinson's Disease among a Diverse Group of Older Adults. Journal of Cross-Cultural Gerontology, 29, 339-352. https://doi.org/10.1007/s10823-014-9233-x

[5] Chan, A.K., McGovern, R.A., Brown, L.T., Sheehy, J.P., Zacharia, B.E., Mikell, C.B., Bruce, S.S., Ford, B. and McKhann, G.M. (2014) Disparities in Access to Deep Brain Stimulation Surgery for Parkinson Disease: Interaction between African-American Race and Medicaid Use. JAMA neurology, 71, 291-299. https://doi.org/10.1001/jamaneurol.2013.5798

[6] Dahodwala, N., Xie, M., Noll, E., Siderowf, A. and Mandell, D.S. (2009) Treatment Disparities in Parkinson's Disease. Annals of Neurology, 66, 142-145.

https://doi.org/10.1002/ana.21774

[7] Cheng, E.M., Siderowf, A.D., Swarztrauber, K., Lee, M., Vassar, S., Jacob, E., Eisa, M.S. and Vickrey, B.G. (2008) Disparities of Care in Veterans with Parkinson's Disease. Parkinsonism \& Related Disorders, 14, 8-14. https://doi.org/10.1016/j.parkreldis.2007.05.001

[8] Willis, A.W., Schootman, M., Evanoff, B.A., Perlmutter, J.S. and Racette, B.A. (2011) Neurologist Care in Parkinson Disease a Utilization, Outcomes, and Survival Study. Neurology, 77, 851-857. https://doi.org/10.1212/WNL.0b013e31822c9123

[9] Branson, C.O., Ferree, A., Hohler, A.D. and Saint-Hilaire, M.H. (2016) Racial Disparities in Parkinson Disease: A Systematic Review of the Literature. Advances in Parkinson's Disease, 5, 87. https://doi.org/10.4236/apd.2016.54011

[10] McInerney-Leo, A., Gwinn-Hardy, K. and Nussbaum, R.L. (2004) Prevalence of Parkinson's Disease in Populations of African Ancestry: A Review. Journal of the National Medical Association, 96, 974-979.

[11] Dahodwala, N., Karlawish, J., Shea, J.A., Zubritsky, C., Stern, M. and Mandell, D.S. (2012) Validation of an Instrument to Measure Older Adults' Expectations Regarding Movement (ERM). PloS One, 7, e43854.

https://doi.org/10.1371/journal.pone.0043854 
Submit or recommend next manuscript to SCIRP and we will provide best service for you:

Accepting pre-submission inquiries through Email, Facebook, LinkedIn, Twitter, etc. A wide selection of journals (inclusive of 9 subjects, more than 200 journals)

Providing 24-hour high-quality service

User-friendly online submission system

Fair and swift peer-review system

Efficient typesetting and proofreading procedure

Display of the result of downloads and visits, as well as the number of cited articles Maximum dissemination of your research work

Submit your manuscript at: http://papersubmission.scirp.org/

Or contact apd@scirp.org 